\title{
APPLICATION OF 3D SCANNING TECHNOLOGY IN RESTORATION OF HERITAGE SITE DAMAGED BY NATURAL DISASTER
}

\author{
Susanna Lai Kuen SIU \\ Executive Secretary (Antiquities and Monuments) \\ Antiquities and Monuments Office, Development Bureau, The Government of the Hong Kong \\ Special Administrative Region of the People’s Republic of China, 136 Nathan Road, Tsim Sha Tsui, \\ Kowloon, Hong Kong, slksiu@amo.gov.hk
}

\begin{abstract}
KEY WORDS: restoration, terrestrial laser scanning, modelling, 3D printing, built heritage, natural disasters, conservation planning, heritage documentation
\end{abstract}

\begin{abstract}
:
Duddell Street Steps and Gas Lamps in Central, Hong Kong (hereafter "the Steps”) is a small site with outstanding heritage value to the city and was therefore declared a monument by the heritage authority in 1979. In 2018, Super Typhoon Mangkhut hit Hong Kong, causing significant damage to the Steps. The Steps were broken into 280 pieces in total. The Antiquities and Monuments Office (“AMO”) set up its 3D Laser Scanning Survey Sub-unit ("3DSU”) in 2016 with the objective of utilising latest technologies to drive innovations in the surveying, recording and conservation of invaluable built and archaeological heritage. Fortunately, a laser scanning survey of the Steps was conducted in early 2018. This went a long way towards facilitating the success of the restoration work, as the project team had a baseline dataset showing the Steps' original state. The ensuing restoration proposal could make reference to the 3D survey data, thus ensuring a complete and faithful restoration. Given the sheer number of broken pieces involved, it was decided that 3D scanning technology would for the first time in Hong Kong be used in parallel with traditional craftsmanship, guided throughout by the highest conservation principles, to help restore a heritage site badly damaged by a natural disaster.
\end{abstract}

This paper illustrates how 3D scanning technology facilitated the restoration works. This project also perfectly exemplified the importance of 'conservation preparedness' for heritage sites facing unpredictable risks from natural disasters.

\section{INTRODUCTION}

Natural disasters, such as typhoons, earthquakes, and floods, have always posed significant and unpredictable threats and caused damage to human lives and built heritage. ${ }^{1}$ The frequency and intensity of such events are nowadays actually increasing due to global warming. In order to maintain the authenticity and sustainability of our sites of built heritage, we should ensure that both their tangible and intangible dimensions are well documented, both for the benefit of future generations and for restoration purposes in the event of damage caused by natural disasters. This approach is fundamental to achieving faithful restorations of damaged built heritage sites according to international conservation charters and principles, such as the Principles for the Conservation of Heritage Sites in China ("The China Principles") ${ }^{2}$ and Burra Charter ${ }^{3}$, which emphasise the importance of research and proven archival materials when restoring built heritage.

In 2018, Super Typhoon Mangkhut brought record-breaking storm conditions to Hong Kong and blew down an adjacent large wall tree causing significant damage to the Steps. The Steps were

\footnotetext{
1 F. Hassani, 2015. Documentation of Cultural Heritage Techniques, Potentials and Constraints, The International Archives of the Photogrammetry, Remote Sensing and Spatial Information Sciences, Volume XL-5/W7, 2015.

2 China Principles, Article 5: "Research is fundamental to every

aspect of conservation. Each step in the conservation process should
}

broken into 280 pieces in total. The 3DSU, which was

established in 2016 with the objective of utilizing latest technologies to drive innovations in the surveying, recording and conservation of invaluable built and archaeological heritage in Hong Kong, conducted a laser scanning survey of the Steps in early 2018, just a few months before the incident. This went a long way towards facilitating the success of the restoration work, as the project team had a baseline dataset showing the Steps' original state. The ensuing restoration proposal could make reference to the $3 \mathrm{D}$ survey data to ensure the monument's complete and faithful restoration. The project team was determined to restore the monument in strict adherence to the conservation principle of using original craftsmanship and materials, supplemented by advanced 3D scanning technology. This was the first time in Hong Kong that a heritage site badly damaged by a natural disaster was successfully restored using advanced 3D scanning technology in parallel with traditional craftsmanship and materials. The restoration work was completed on 23 December 2019, when Hong Kong's four surviving historic gas lamps were relit to illuminate the century- 
old granite steps.

In the following sections, the author will introduce the processes involved in the restoration work in order to illustrate the ways in which 3D scanning technology was used to facilitate the restoration work, while also aiming to show how heritage documentation also played a crucial role in the success of this restoration project. In the final part, the author looks ahead to explore the new technologies that could enhance the documentation of built heritage in Hong Kong so as to maintain their heritage values and sustainability.

\section{SIGNIFICANCE OF THE STEPS}

The Steps, which are mainly constructed of granite and have an elaborate architectural design, are one of the city's few intact examples of nineteenth-century historic streetscape. When constructed, the monument embodied a perfect blend of local craftsmanship, such as granite stonemasonry, and advanced Western technology in the form of gas-powered street lighting. With the city-wide electrification of street lighting in 1967, the four historic gas lamps became the only surviving examples to have continued in use in Hong Kong. The Steps still serve their original function as a thoroughfare used by many pedestrians each day. The monument is an outstanding historical and social landmark for Hong Kong people. In view of their outstanding heritage value, the Steps were declared a monument under the Antiquities and Monuments Ordinance (Cap. 53) (“A\&M Ordinance”) in 1979 and have become a renowned historical and social landmark in the city.

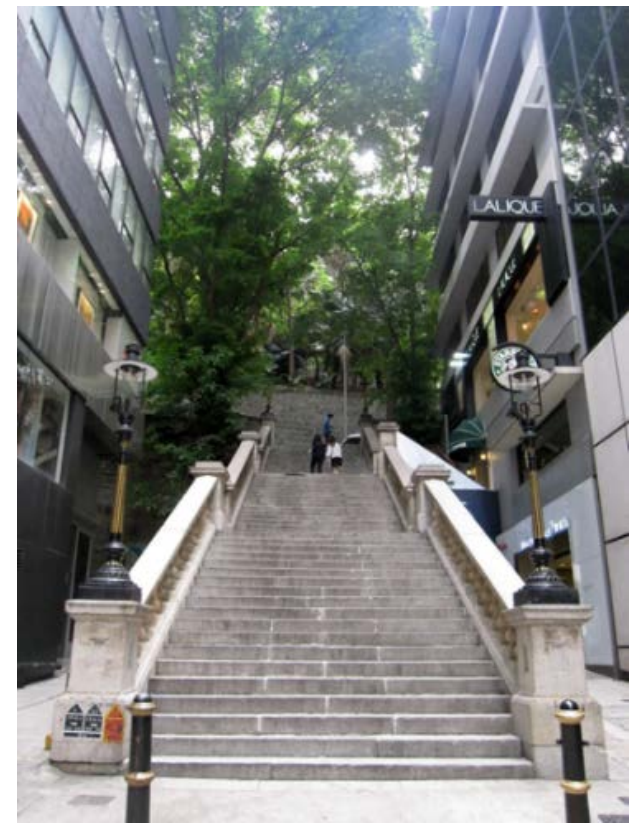

Figure 1: Duddell Street Steps and Gas Lamps, Central, Hong Kong before damage.

\section{THE ESTABLISHMENT OF THE AMO'S 3DSU}

With firm support from the Commissioner for Heritage’s Office

\footnotetext{
${ }^{4}$ The CHO is under the Development Bureau (DEVB) of the Government of the Hong Kong Special Administrative Region.

5 The Antiquities Authority may, after consultation with the AAB and
}

("CHO"), ${ }^{4}$ the AMO put forward a new initiative to enhance the government's efforts in heritage conservation in Hong Kong, which was in turn a response to concerns raised by the Antiquities Advisory Board ("AAB") regarding the need for the proper recording of Hong Kong's built heritage, for operational, archival and public appreciation purposes. The new initiative aimed to leverage the benefits of advanced surveying technologies in order to bring innovations in the surveying, drawing and recording of invaluable built and archaeological heritage for purposes of conservation and education. Finally, the 3DSU was set up in 2016. With state-of-the-art 3D scanning instrumentation, Hong Kong's declared monuments ${ }^{5}$ would be accurately measured and recorded in detail. The ultimate goal of setting up the 3DSU was to establish a repository of 3D as-built survey records of all the declared monuments in Hong Kong. The geometrically accurate records significantly enhance the monitoring and reproduction of damaged objects, which can play a crucial role when carrying out built heritage restoration and maintenance works. The 3D records can also be converted into two-dimensional drawings and photo images for various purposes.

\section{PRE-INCIDENT RECORD FIELD SURVEY}

The Steps were fortunate enough to be within the first batch of declared monuments in Hong Kong selected to be laser scanned in early 2018. A set of comprehensive as-built survey data for the Steps was captured for future monitoring, maintenance, restoration and educational purposes. Two different types of 3D scanners were used for this work, as detailed below.

\subsection{Terrestrial Laser Scanner}

The first was a medium-range, phase-shift based terrestrial laser scanner, which emits laser beams towards a physical object and receives their reflections. The distance between the object and the scanner is then calculated by analysing the phase shift in the wavelength of the reflected beam against the emitted beam, while at the same time measuring and recording the direction of the beams. The scanning process allows the object's surface to be described and recorded as dense measurement points and, in turn, the object's geometric shape can then be reconstructed in the computer environment. The acquired survey data are recorded in clusters of measurement points, commonly referred to as "point clouds". In practice, the survey process typically involves scanning from different perspectives at different locations in order to acquire comprehensive survey records of the object. During post-processing, the point clouds captured at various scanner locations are registered into a common 3D Cartesian coordinate reference frame within which their geometrical relationships with one another are corrected. This type of scanner is particularly suitable for the recording of the built environment. Through careful pre-survey planning of the scanner locations, comprehensive survey records of the built environment can be acquired.

\subsection{Portable 3D Scanner}

The second type of scanner used was a portable 3D scanner that employs a different working principle known as triangulation. Before using this type of scanner, reflective targets are first attached to the object and/or its surroundings to establish an

with the approval of the Chief Executive, by notice in the Gazette, declare a place, building, site, or structure as a monument. A declared monument is protected by the Antiquities and Monuments Ordinance. 
arbitrary 3D Cartesian coordinate reference frame. This ensures the measurement points acquired at ever-changing scanner positions and orientations relative to the object at different times can be geometrically registered. The scanner shines a laser dot on the object's surface and exploits a camera to look for it. The laser dot, the camera, and the laser emitter form a triangle in the 3D space. While the length of one side of the triangle (i.e. the base distance between the camera and the laser emitter) and the adjacent angle (i.e. the direction of the emitted laser-beam measured from the base) are both fixed and known, the other adjacent angle can be derived by analysing the location of the laser dot in the camera's field of view. With these three pieces of information, the shape and size of the triangle can be determined, and this, in turn, gives the actual 3D location of the laser dot with reference to the scanner's coordinate system. The object's surface can be digitally constructed on the fly in the form of triangular meshes or point clouds during the scanning process. A portable 3D scanner is suitable for recording architectural components and small objects due to its ability to survey fine details at a resolution of $0.050 \mathrm{~mm}$.

\begin{tabular}{|l|l|l|l|}
\hline $\begin{array}{l}\text { Faro Focus3D X330 } \\
\text { (Terrestrial Laser Scanner) }\end{array}$ & \multicolumn{2}{|l|}{$\begin{array}{l}\text { Creaform HandySCAN 700 } \\
\text { (Portable 3D Scanner) }\end{array}$} \\
\hline Range & $0.6 \mathrm{~m}-330 \mathrm{~m}$ & Depth of Field & $250 \mathrm{~mm}$ \\
\hline $\begin{array}{l}\text { Measurement } \\
\text { Speed }\end{array}$ & $976,000 \mathrm{pts} / \mathrm{s}$ & $\begin{array}{l}\text { Measurement } \\
\text { Rate }\end{array}$ & $\begin{array}{l}480,000 \\
\text { measurements } \\
\text { /second }\end{array}$ \\
\hline $\begin{array}{l}\text { Ranging } \\
\text { Error }\end{array}$ & $+/-2 \mathrm{~mm}$ & Accuracy & $\begin{array}{l}\text { Up to 0.030 } \\
\mathrm{mm}\end{array}$ \\
\cline { 3 - 4 } & & Resolution & $0.050 \mathrm{~mm}$ \\
\hline
\end{tabular}

Table 1: Key technical parameters of AMO’s In-house 3D scanners

On 29 January 2018, the 3DSU carried out a 3D scanning survey of the gas lanterns using the portable 3D scanner. Reflective targets were stuck on both the lantern and its surroundings before each scanning episode; scanning was then performed while the triangular meshes were constructed by the bundled software on the fly. Photographs of the lantern were also taken such that a photorealistic texture could be applied to the final mesh model.

On 1 February 2018, another 3D scanning survey was conducted on-site at Duddell Street using the terrestrial laser scanner to acquire a comprehensive record of the Steps. For this purpose, it was decided that the scanning data be collected at a resolution of $6 \mathrm{~mm}$ (i.e. point spacing of $6 \mathrm{~mm}$ at a distance of $10 \mathrm{~m}$ ). In order to maintain an adequate overlap between adjacent scans and also to reduce blackout areas due to obstructed lines of sight, a total of 23 scans were eventually made at different locations. To achieve the best possible geometrical accuracy, spherical reference targets were placed throughout the site in such a way that there were at least three common reference spheres present in adjacent scans. All 23 scans were then registered into one by utilising the reference spheres as constraints for computing transformation matrices back in the office.

\section{RESTORATION OF THE STEPS}

On 16 September 2018, Super Typhoon Mangkhut, which brought damaging winds and record-breaking storm surges to Hong Kong, blew down an adjacent large wall tree, causing significant damage to the monument. Looking up from Duddell Street, the granite handrail on the left had collapsed, and 47 out

\footnotetext{
${ }^{6}$ Amongst the 280 broken pieces, 34 were from the gas lamps and 204 from the cement balusters (the remaining pieces are granite railings,
}

of the 101 cement balusters were either badly crushed or broken into multiple fragments. Three out of the four century-old gas lamps had collapsed, and their lanterns had been severely damaged and deformed. Worse still, one of the gas lamp's castiron columns was broken into several pieces. The damage was so serious that the monument seemed ostensibly beyond repair.
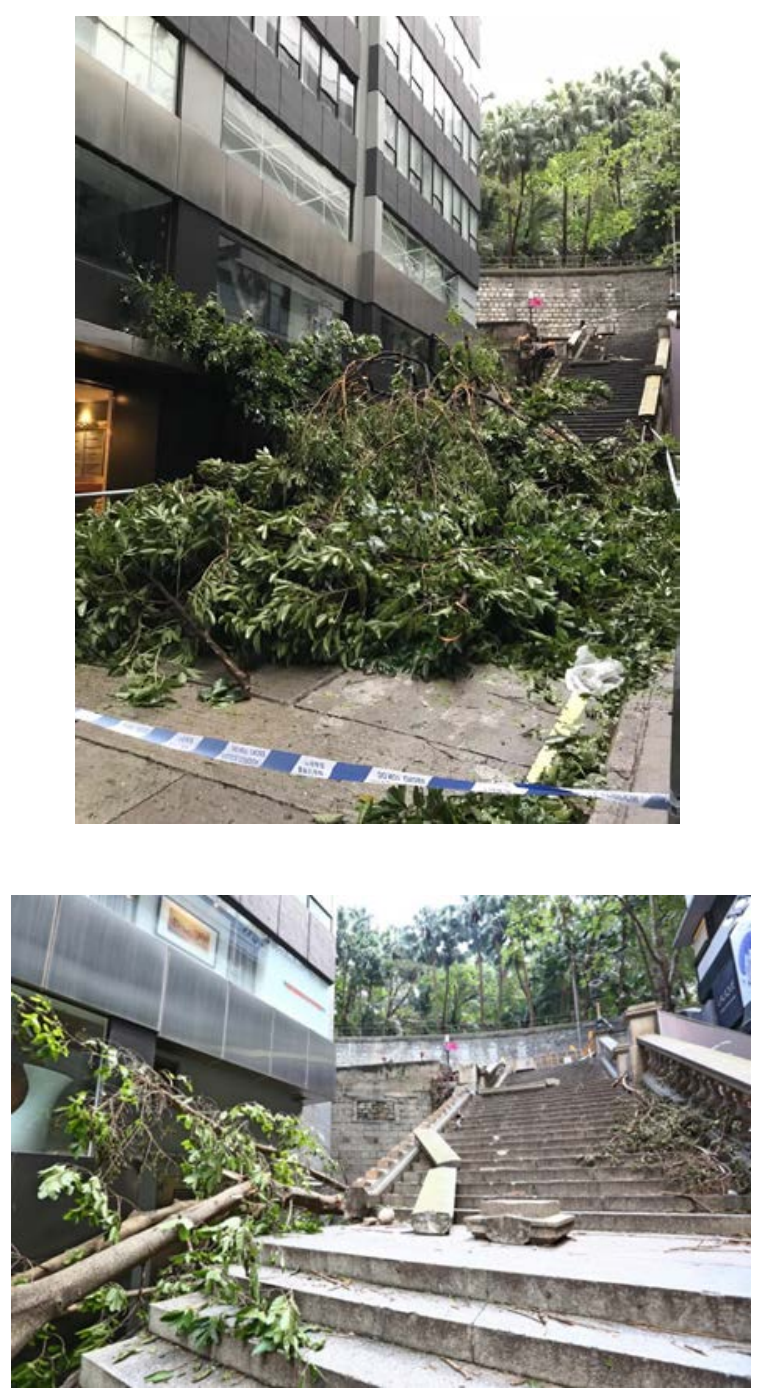

Figures 2 and 3: The Steps were seriously damaged by the fallen wall tree.

The project team was determined to achieve a faithful restoration of the monument by reusing the damaged original materials and employing traditional craftsmanship. Immediately after the incident, the AMO, Highways Department ("HyD”), and The Hong Kong and China Gas Company Limited ("Towngas") began to document and salvage the broken pieces scattered across the site. In total, 280 damaged parts were salvaged, ${ }^{6}$ sorted and accessioned before being packed and relocated to storage for detailed inspection and safekeeping pending restoration. Regardless of its size, every single fragment of the monument was carefully recorded and collected for future restoration. At the same time, the AMO's staff conducted research on the Steps' history and past maintenance records from existing in-house archives and other media.

newels and other components). 


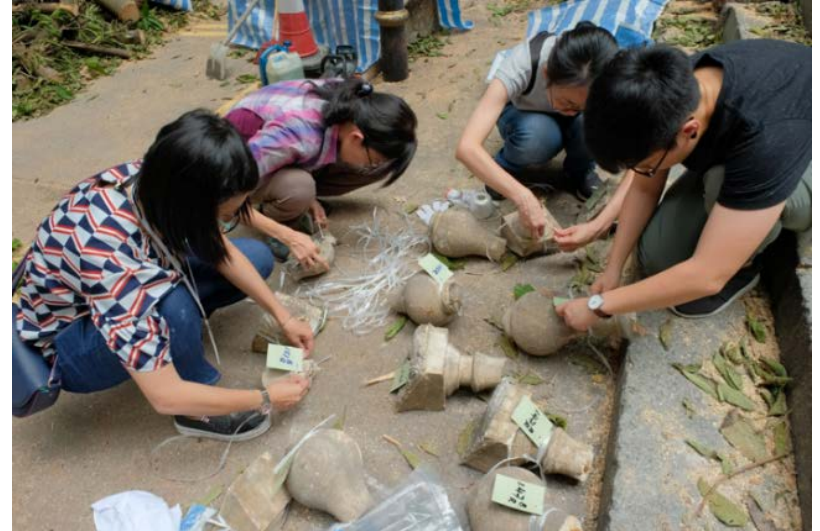

Figure 4: AMO staff salvaging and accessioning the broken parts of the Steps.

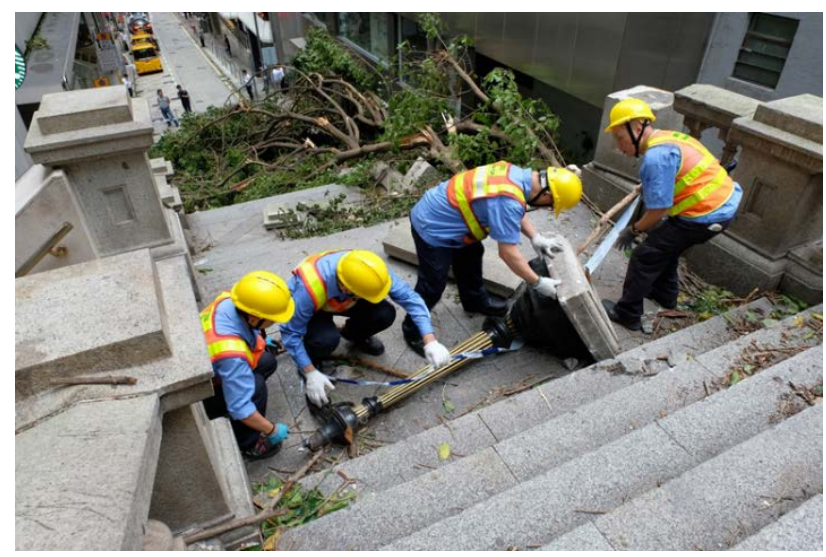

Figure 5: Towngas staff salvaging the broken cast iron column of the gas lamp.

\section{POST-INCIDENT FIELD SCANNING SURVEY}

Given the sheer number and the huge size of some of the broken pieces involved, it was decided that 3D scanning technology should be used. The 3DSU scanned the damaged monument onsite in order to capture its condition after the incident. On 2 October 2018, once the site was cleared, a 3D scanning survey was conducted on-site using the terrestrial laser scanner to capture the post-incident situation and to help facilitate its later restoration. A total of 14 scans were made at a $6 \mathrm{~mm}$ resolution. While spherical reference targets were placed throughout the site in such a way that there were at least three common reference spheres present in adjacent scans, certain spherical reference targets were also placed over existing survey stations fixed by HyD. Back in the office, all the scans were registered into one and georeferenced horizontally to the HK1980 Grid coordinate system and vertically to the Hong Kong Principal Datum.

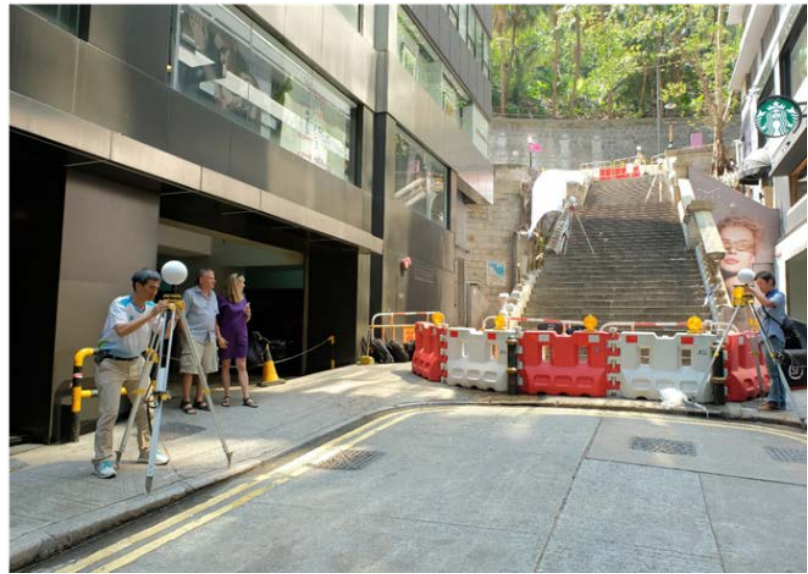

Figure 6: 3DSU conducting 3D laser scanning by terrestrial laser scanner on site after the damage.

Another on-site 3D scanning survey was conducted using the portable 3D scanner to record the surviving structures at the sides of the Steps. Reflective targets were firstly attached to the surfaces of the Steps, and the scanning was then performed while its digital replica were constructed on the fly in the form of triangular meshes. Photographs were taken so that a photorealistic texture could, if necessary, be applied to the final mesh model.

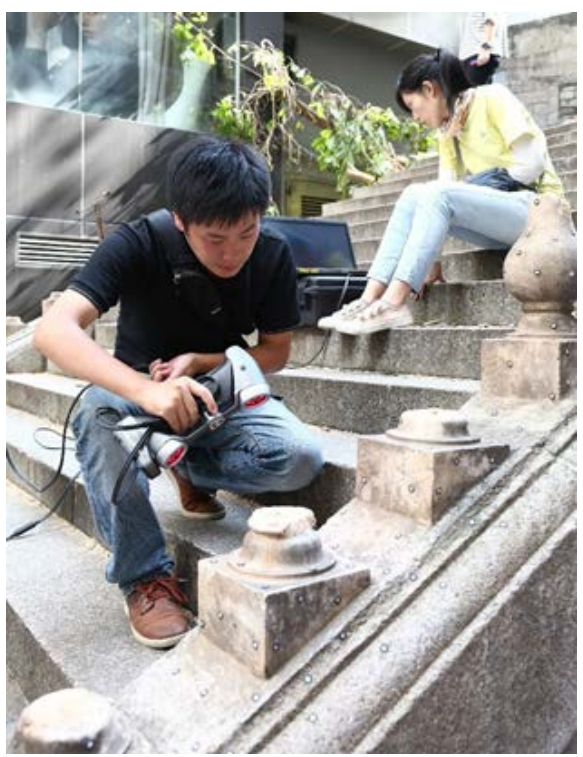

Figure 7: 3DSU using a portable 3D scanner to scan the surviving structures on site.

All major granite fragments relocated to HyD's store for temporary storage were also scanned using the portable 3D scanner in order to acquire accurate data for their shapes and dimensions. Instead of attaching the reflective targets onto the granite fragments, in this case they were stuck onto plastic or metal frames available at the store. Once prepared, these frames could then be placed stably over each granite fragment in turn, thereby reducing the set-up time and speeding up the scanning process. Photographs were taken to supplement the scanning data. 


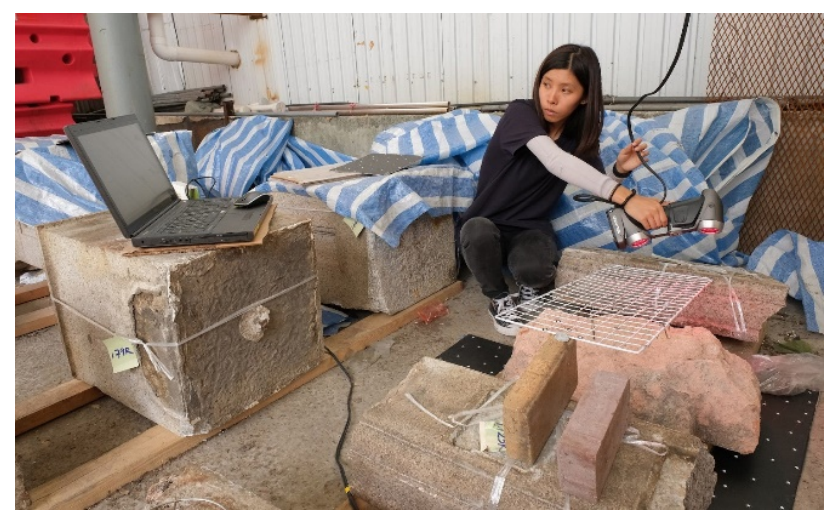

Figure 8: 3DSU using the portable 3D scanner to scan the large granite fragments at HyD’s store.

\section{SCANNING DATA POST-PROCESSING AND 3D PRINTING}

The incident scene and major granite fragments had been digitally captured in the form of a registered point cloud and triangular meshes, respectively.

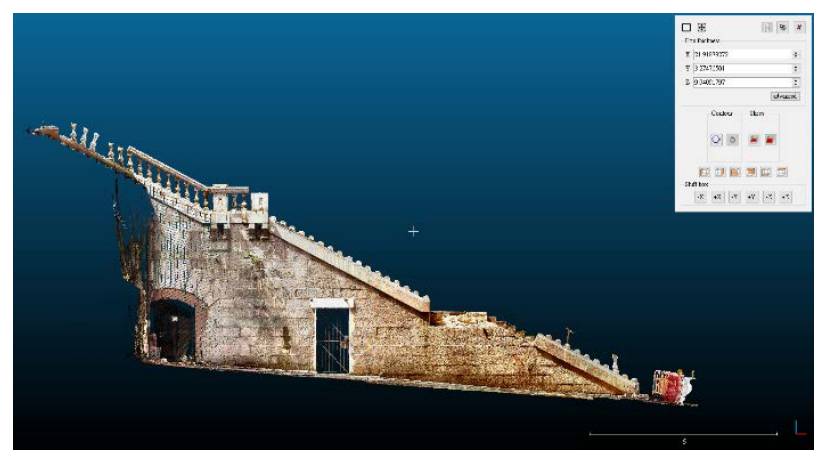

Figure 9: Point cloud of the Steps obtained after damage.

Various modelling software packages, such as CloudCompare, Geomagic and 3DReshaper, were used to further process the georeferenced point cloud and the triangular meshes. The steps taken in this stage included:

1. perform data cleaning manually on the point clouds / triangular meshes to remove unwanted data due to obstacles and pedestrians passing through the survey area;

2. perform triangulation on the cleaned point clouds and generate triangular meshes using the software's builtin algorithms, where applicable;

3. perform first round of automatic mesh fixing operation;

4. perform second round of manual mesh fixing, such as filling holes and correcting abnormal triangular faces;

5. convert open meshed surfaces into closed airtight meshed solid, if applicable; and

6. segment the meshed model of the scene into separate parts for subsequent 3D printing at a scale agreed by the restoration team, due to the limitation in build size of the 3D printer.

Miniature replicas of the granite fragments were 3D-printed and given numbers identical to those assigned to their full-size granite originals. These replicas were used for desk-top investigation and as a means of devising an appropriate restoration approach. They were also reassembled to reconstruct the scene in the office, which would help facilitate the fragments' future reassembly on site. The team reassembling the granite fragments on-site could then work according to the model and reassembly procedure prepared by the project team. The restoration work could thus be done accurately and efficiently. As a consequence, the time required and costs involved in the on-site restoration work were significantly reduced. More importantly, the level of inconvenience caused to the users of the Steps by their closure was greatly reduced.

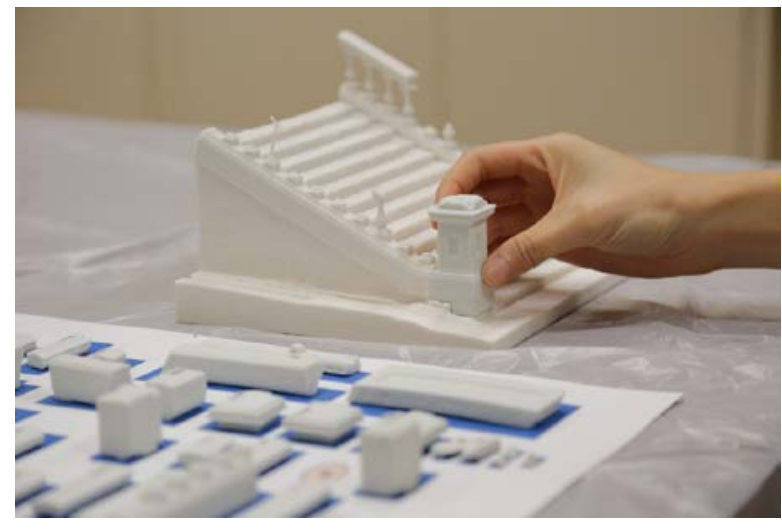

Figure 10: Miniature replicas of numbered granite fragments were 3D-printed and reassembled in the office.

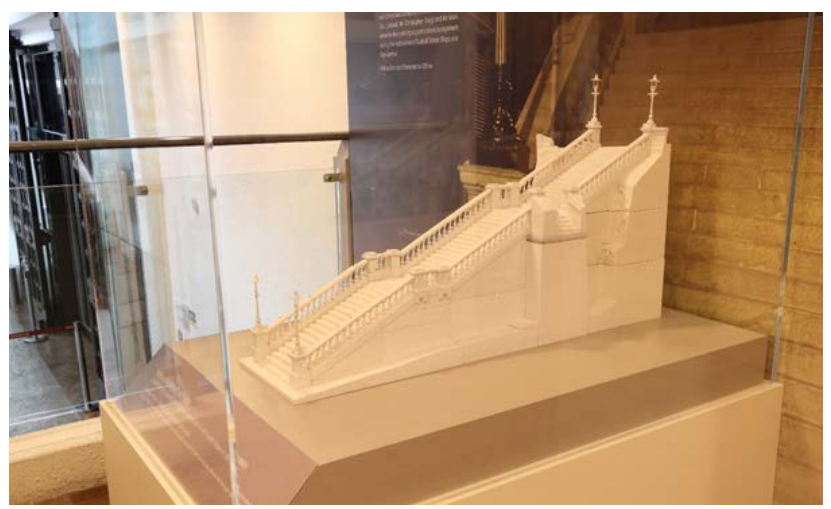

Figure 11: The reassembled Steps model using the 3D printed miniature replicas of numbered granite fragments.

After the completion of the restoration work, the 3DSU once again conducted 3D scanning to obtain a complete and up-todate survey dataset for proper documentation of the fully restored monument. 


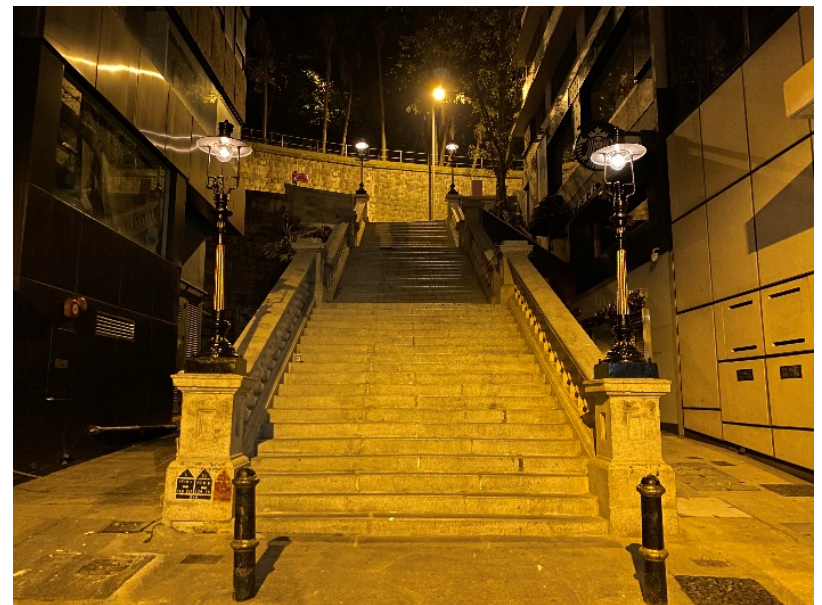

Figure 12: The Steps after restoration works completed.

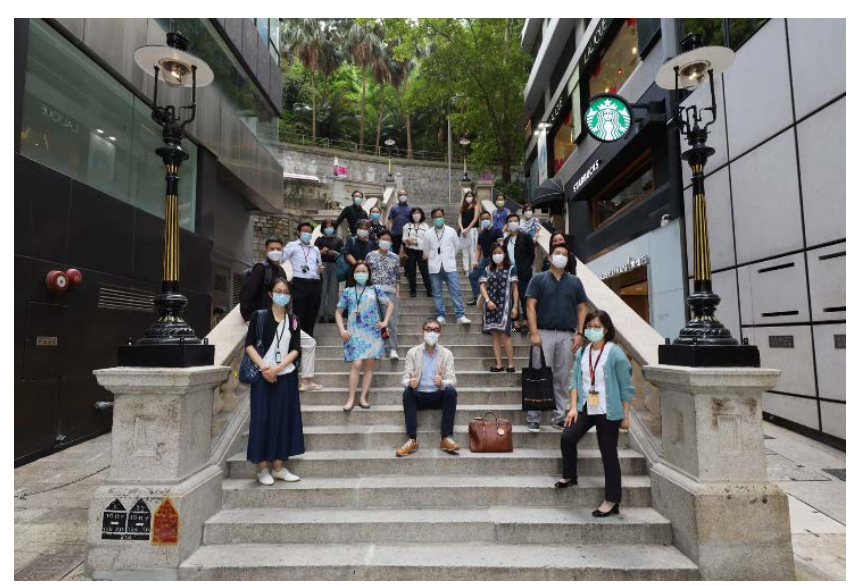

Figure 13: $\mathrm{CHO}$ and $\mathrm{AAB}$ members visited the Steps after restoration works completed.

\section{SUSTAINABILITY OF DOCUMENTATION}

The experience gained through this project was recorded in various forms, such as exhibitions, videos, photographs, and digital as-built survey records. This documented information facilitated the transmission of the heritage conservation knowledge and experience gained from this restoration project to other heritage conservation practitioners and the general public, and significantly enriched the archive for this precious piece of Hong Kong's built heritage.
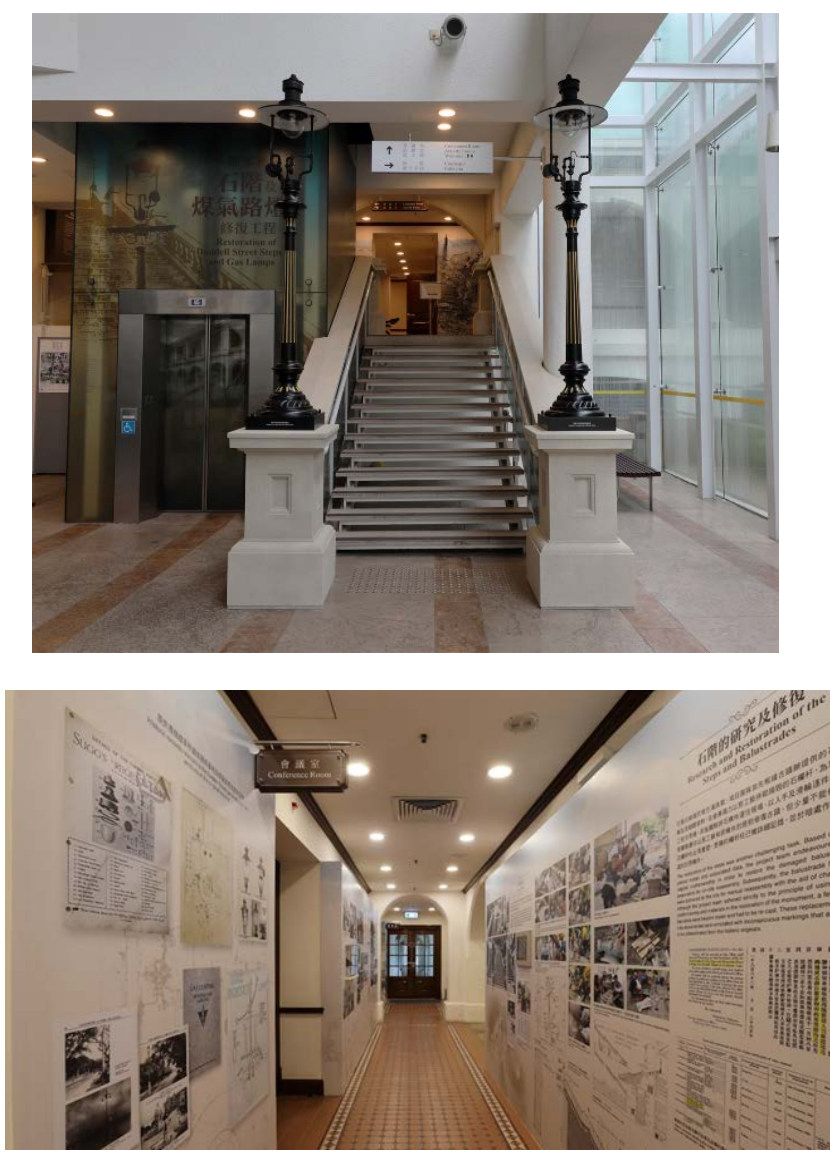

Figures 14 and 15: An exhibition showing the restoration works of the Steps staged at the Hong Kong Heritage Discovery Centre

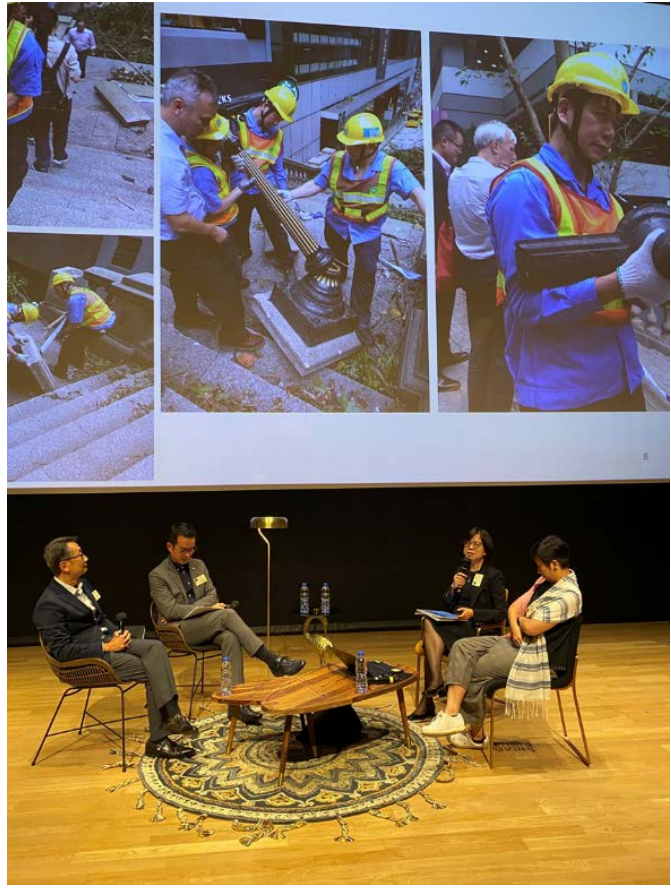

Figure 16: The project teams shared the restoration experience in a public lecture. 
Recognising the potential of digital technologies to facilitate and expedite the documentation process, while also ensuring more precise and accurate outputs for establishing conservation plans, the AMO is exploring other new and advanced technologies to enhance built heritage documentation. For instance, Phase One camera, a professional camera capable of very high resolutions, was introduced by the AMO with the aim of being able to capture very fine architectural features of important built heritage from some distance away.

In addition, the use of drones and artificial intelligence algorithms to assist in the inspection of the roofs of heritage buildings, to generate measurements and defect reports, and allow inspection data comparison through time will be implemented subject to availability of funding. The technology would provide an automated, cloud-based and fully streamlined workflow during inspections, data collection and processing. In contrast to conventional roof inspections, which require the erection of scaffolding that will remain in place throughout the inspection period, roof inspections by drone can avoid the erection of extensive scaffolding for access to the roof, thus minimising the inconvenience caused to the building's users and visitors. The raw drone photos taken from the air, if properly planned, allow geometrically accurate 3D models with photorealistic textures to be generated for roofs, which in turn fills in the gap used to exist due to the limitation of terrestrial laser scanning. When the drone is equipped with an infrared camera, thermal imaging can be obtained to identify any hidden areas of water leakage on the roof. All these data will be extremely useful for building inspection, maintenance, and repair, and also for staff training purposes.

\section{CONCLUSIONS}

Before the advent of 3D scanning and information technologies, the repair and maintenance of built heritage relied upon traditional measurement and visual inspection methods, which are very time consuming and not particularly accurate. The new initiatives of introducing 3D scanning technology provide accurate and detailed measurements of the monuments, which form the basis for monitoring and restoration works and facilitate and expedite the documentation process. This study demonstrated that 3D scanning technology played an indispensable role in the Duddell Street project, such that the restoration could be carried out in compliance with the highest international conservation standards. The precious experience gained in utilising 3D scanning technology in this restoration project provides a benchmark for the future restoration of heritage sites in Hong Kong. More importantly, this case study illustrated the critical importance of good heritage documentation as the basis for conservation preparedness when encountering the damage brought by unforeseen natural disasters. ${ }^{7}$ Such documentation should be regularly and appropriately updated and reviewed. New tools and technologies have offered new opportunities in conserving built heritage and should be wisely adopted.

\section{ACKNOWLEDGEMENTS}

The author would like to thank the AAB, the CHO, HyD, Towngas, her team members particularly Dr Mick Atha, Fanny Kong and Kelvin King and all those involved in the restoration works for their unfailing support, tremendous effort and devotion to the task.

\section{REFERENCES}

Australia ICOMOS, 2013. Burra Charter: the Australia ICOMOS Charter for places of cultural significance, 1st draft in 1979, Australia.

F. Hassani, 2015. Documentation of Cultural Heritage Techniques, Potentials and Constraints, The International Archives of the Photogrammetry, Remote Sensing and Spatial Information Sciences, Volume XL-5/W7, 2015.

International Centre for the Study of the Preservation and Restoration of Cultural Property (ICCROM). 1998. Risk Preparedness: A Management Manual for World Cultural Heritage, Rome.

ICOMOS China. 2015. Principles for the Conservation of Heritage Sites in China. Rev. Beijing.
${ }^{7}$ International Centre for the Study of the Preservation and Restoration of Cultural Property (ICCROM). 1998. Risk Preparedness: A
Management Manual for World Cultural Heritage, Rome. 